\title{
Лечение ишемической формы синдрома диабетической стопы
}

\author{
В. В. Бойко ${ }^{1}$, Ю. В. Иванова ${ }^{1}$, И. А. Криворучко ${ }^{2}$, С. Н. Диденко ${ }^{3}$, Е. В. Мушенко \\ А. М. Коробов ${ }^{4}$ В. А. Прасол ${ }^{1}$, В. В. Шафранский \\ ${ }^{1}$ Институт общей и неотложной хирургии имени В. Т. Зайцева НАМН Украины, г. Харьков, \\ ${ }^{2}$ Харьковский национальный медицинский университет, \\ ${ }^{3}$ Клиническая больница «Феофания», г. Киев, \\ ${ }^{4}$ Харьковский национальный университет имени В. Н. Каразина \\ ${ }^{5}$ Национальний медицинский университет имени А. А. Богомольца
}

\section{Treatment of ischemic form of the diabetic foot syndrome}

\author{
V. V. Boyko' ${ }^{1}$, Yu. V. Ivanova ${ }^{1}$, I. A. Krivoruchko², S. N. Didenkoㄹ, E. V. Mushenko', \\ A. M. Korobov ${ }^{4}$, V. A. Prasol ${ }^{1}$, V. V. Shafranskyi \\ ${ }^{1}$ Zaytsev Institute of General and Urgent Surgery Ukraine, Kharkov, \\ ${ }^{2}$ Kharkov National Medical University, \\ ${ }^{3}$ Clinical Hospital «Feofania» State Directorate for Affairs, Kyiv, \\ ${ }^{4}$ V. N. Karazin Kharkov National University \\ ${ }^{5}$ Bogomolets National Medical University, Kyiv
}

Реферат

Цель. Сравнить эффективность традиционной терапии и комплексного лечения с использованием фотодинамической терапии и тромбоцитарного фактора роста для улучшения результатов лечения пациентов с синдромом диабетической стопы.

Материал и методы. В исследование включено 11 пациентов с ишемической формой синдрома диабетической стопы (СДС), лечившихся в клинике Института общей и неотложной хирургии имени В. Т. Зайцева НАМН Украины в 2016 - 2017 гг. Помимо стандартных методов обследования - лабораторных и инструментальных, проводили исследование кислороднезависимого и кислородзависимого фагоцитоза. Рассчитывали общую площадь дефекта, относительную площадь некроза, грануляционной ткани и эпителизации, а также скорость заживления ран. Статистическую обработку результатов исследования выполняли с помощью программы «Microsoft Excel». В комплекс лечения, помимо эндоваскулярной реваскуляризации конечностей и медикаментозной терапии, включали фотодинамическую терапию и фототерапию по разработанной методике. В качестве фотосенсибилизатора использован $35 \%$ раствор димегина. После устранения ишемии, очищения язв применяли различные способы пластического закрытия дефекта. Для ускорения заживления язв их закрывали синтетическим покрытием с использованием плазмы, обогащенной тромбоцитарным фактором роста.

Результаты. Применение разработанного алгоритма позволило сократить сроки очищения язв от гнойно-некротических масс, что наблюдалось уже на 2 - 3-и сут лечения. Также сократились сроки появления первых грануляций и краевой эпителизации, что отмечалось на 4 - 5-е и 6 - 7-е сут лечения соответственно. При этом уровень инфицированности язв снижался ниже критических величин на 6 - 7-е сут, что благоприятно влияло на скорость их заживления. В процессе лечения ни в одном наблюдении не потребовалось выполнения этапных некрэктомий. Также во всех случаях удалось избежать ампутации конечностей.

Выводы. Использование предлагаемого подхода у пациентов с СДС позволяет улучшить результаты лечения за счет ускорения процессов заживления ран, снизить количество ампутаций.

ключевые слова: диабетическая стопа; язвообразование; фотодинамическая терапия.

Abstract

Objective. To compare efficacy of conventional therapy and complex treatment, using photodynamical therapy and plateletderived growth factor, for the treatment results improvement in patients, suffering diabetic foot syndrome.

Materials and methods. There were investigated 11 patients, suffering an ischemic form of the diabetic foot syndrome (DFS), who were treated in the clinic of Institute of General and Urgent Surgery named after V. T. Zaytsev NAMS of Ukraine in 2016 - 2017 yrs. Besides standard methods of examination - laboratory and instrumental - investigation of the oxygenindependent and oxygen-dependent phagocytosis was conducted. General square of the defect, relative square of necrosis, granulation tissue and epithelization, as well as velocity of the wounds healing, were calculated. Statistical elaboration of the investigation results was performed, using «Microsoft Excel» program. Besides endovascular revascularization of the extremities and medicinal therapy, photodynamical therapy and phototherapy in accordance to procedure elaborated were included into complex of treatment. As a photosensitizer a 35\% solution of dimegin was used. Various methods of plastic closure of defects were applied after elimination of ischemia and the ulcers clearance finished. For the ulcers healing acceleration they were covered with synthetic coverage, using plasm, enhanced by platelet-derived growth factor.

Results. Application of the algorithm elaborated permits to shorten the ulcers clearance terms from purulent-necrotic masses down to $2-3$ days of treatment. The terms of first granulations and the edge epithelization have shortened also, and was noted on the $4-5$ th and $6-7$ th days of treatment, accordingly. The ulcers infectioning level have lowered down to critical values on $6-7$ th days, favorably affecting velocity of its healing. In the treatment process the need for conduction of staged necrectomies was absent. As well, in all the cases the extremities amputation have been avoided.

Conclusion. Application of the approach proposed in patients, suffering DFS, permits to improve the treatment results due to acceleration of the healing processes and the amputation performance lowering.

Keywords: diabetic foot; development of ulcer; photodynamical therapy. 
Глобальной проблемой современного мира стала постоянно растущая антибиотикорезистентность, в том числе и у пациентов с СДС [1]. Быстрая приспособляемость бактерий и отсутствие принципиально новых классов антибиотиков делают актуальными поиск и внедрение альтернативных, в том числе физических, методов борьбы с антибиотикорезистентными штаммами микроорганизмов [2]. Одним из таких методов является фотодинамическая терапия (ФДТ). В ее основе лежит светоиндуцированная химиотерапия, которая подразумевает обязательное наличие трех факторов: двух экзогенных - фотосенсибилизатора (ФС) и света, одного эндогенного - кислорода и применение фракционированной аутологичной плазмы, обогащенной тромбоцитарным фактором роста (ТФР) [3].

Цель исследования: сравнить эффективность традиционной терапии и комплексного лечения с использованием ФДТ и ТФР для улучшения результатов лечения пациентов с СДС.

\section{Материалы и методы исследования}

В исследование включено 11 пациентов с ишемической формой СДС на фоне сахарного диабета (СД) II типа, которые находились на лечении в клинике Института общей и неотложной хирургии имени В. Т. Зайцева НАМН Украины в 2016 - 2017 гг. Средний возраст больных составил $(58 \pm 2,4)$ года.

Диагноз устанавливали на основании жалоб пациента, анамнестических данных, объективного осмотра. Использовали классификацию PEDIS [4].

Площадь поверхности ран определяли при помощи программы морфометрии «SEO Image Lab 2.0» (г. Сумы, Украина). Рассчитывали общую площадь дефекта, относительную площадь некроза, грануляционной ткани и эпителизации. Скорость заживления ран оценивали путем расчета величины относительного заживления ран (V), предложенной М. И. Кузиным и соавторами [5].

При поступлении у больных осуществляли забор материала для микробиологического исследования. При наличии признаков системного воспалительного ответа (3 наблюдения) обязательно выполняли бактериоскопию. На основании полученных данных назначали стартовую антибактериальную терапию. Проводили микробиологическое исследование раневого отделяемого, определяли количественный и качественный состав микрофлоры, а также чувствительность ее к антибиотикам. Следует отметить, что у 8 пациентов определяли множественно резистентные, у 3 - панрезистентные штаммы возбудителей.

Всем пациентам, помимо общеклинических, биохимических, коагулогических методов исследования, определения суточного гликемического профиля, выполняли рентгенографию костей стопы, допплерографию магистральных сосудов при помощи аппаратов General Electric Logiq 700i «Toshiba» Nemiro XG SSA-580A с использованием датчиков 4 - 5 МГц - для крупных и 8 - 10 МГц - для средних и мелких сосудов.

Степень ишемии оценивали по классификации Fontaine-Покровского [6]. У всех пациентов констати- ровали критическую ишемию IVa степени. Прогностическим критерием заживления ран является транскутанное напряжение кислорода в тканях, которое определяли при помощи оксимонитора ТСМ-4 («Radiometer», Дания). У исследуемых пациентов этот показатель был ниже 40 Па.

Показания к реваскуляризации нижних конечностей устанавливали на основании критериев рабочей группы TASK II [6]. Исследуемые пациенты отнесены к классам А и В.

Активность нейтрофилов оценивали по поглощению и элиминации микробных тел полиморфноядерными лейкоцитами и моноцитами периферической крови, способными связывать на своей поверхности, поглощать и переваривать микробную тест-культуру.

Исследовали кислороднезависимый и кислородзависимый фагоцитоз различными методами. Визуальный метод световой микроскопии позволял оценить адгезию. Проникновение и эндоцитоз бактериальных антигенов оценивали по таким показателям:

фагоцитарный индекс (ФИ) - процент клеток, вступивших в фагоцитоз, от общего их числа;

фагоцитарное число (ФЧ) - среднее число бактерий, находящихся внутриклеточно (частное от деления общего числа поглощенных бактерий на число клеток, вступивших в фагоцитоз).

ФИ и ФЧ рассчитывали после обработки мазков, сделанных после 30- и 90-минутной инкубации (ФИ 30, ФИ 120 и ФЧ 30, ФЧ 120).

Кислородзависимый фагоцитоз оценивали с помощью НСТ-теста (тест восстановления нитросинего тетразолия) по ферментативной активности нейтрофилов, обеспечивающих образование активных форм кислорода (АФК) в спонтанных и индуцированных зимозаном пробах.

Лечение назначали по следующей схеме: компенсация СД (перевод на дробную инсулинотерапию), метаболическая, антибактериальная, антикоагулянтная и ангиотропная терапия, физические методы лечения.

В комплексе местного лечения ран использованы фотонные матрицы «Барва флекс» А. М. Коробова с различным спектральным диапазоном: длина волны ( $\lambda$ ) 660, 470, 525, 405 нм, что соответствовало красному, синему, зеленому и фиолетовому свету, имеющему различные эффекты [7].

Нами разработана и применена следующая схема лечения СДС. На этапе подготовки к ФДТ при наличии выраженного отека проводили 3 - 5 сеансов фототерапии (ФТ) синим светом ( $\lambda 470$ - 440 нм, длительность сеанса -5 - 10 мин). При отсутствии перифокального отека подготовка ран к ФДТ включала проведение 3 - 5 сеансов ФТ зеленым светом ( $\lambda 550$ - 520 нм, длительность сеанса - $3-5$ мин). Доза подводимой к ране энергии составляла в среднем $30-40$ Дж/см². Плотность мощности света была в пределах 0,1 - 1,0 Вт/см², а время воздействия на рану варьировало в зависимости от ее площади.

В период подготовки ран к Фдт параллельно проводили реваскуляризацию конечностей. У всех исследуемых пациентов выполняли эндоваскулярные вмеша- 
тельства. В зависимости от локализации поражения стопы выбирали артерию для реканализации (пяточная область - задняя большеберцовая артерия, передний отдел стопы - передняя большеберцовая артерия).

При необходимости выполняли хирургическую обработку ран с ликвидацией гнойных затеков. На следующие сутки после хирургической обработки в области дна и краев ран сохранялись очаги некрозов и налет фибрина. После туалета ран 3\% раствором перекиси водорода на рану накладывали марлевую салфетку, пропитанную ФС, которая находилась в ране в течение 20 мин. В качестве ФС использовали 35\% раствор димегина - динатриевая соль 2,7,12,18-тетраметил-3,8-ди(1-метоксиэтил)-13,17-ди(2-оксикарбонилэтил) порфирина. Препарат характеризуется длительной элиминацией из организма, что удлиняет его бактерицидный эффект в ране. Из-за выраженной кожной фототоксичности его необходимо осторожно применять и предотвращать попадание ФС на неповрежденные ткани. После удаления салфетки с ФС рану облучали фиолетовым или синим светом ( $\lambda 405$ или 470 нм).

После проведения курса ФДТ переходили на ФТ: облучение ран красным светом ( 2660 - 630 нм) ежедневно (длительность сеанса - 10 - 15 мин, кратность - 10 - 12 в зависимости от площади ран) до появления условий для выполнения пластического закрытия дефектов. Ксенотрансплантация в качестве пластического метода была применена у 4 пациентов. В 7 наблюдениях раневые дефекты закрывали синтетическим покрытием поликапролактон - PCL (Nanopharma, Чехия) с аппликацией фибринового сгустка и плазмы, обогащенной ТФР без фибрина. Данная методика заключалась в следующем. Осуществляли забор 20 мл крови без консерванта из локтевой вены и ультрацентрифугирование ее для получения фракции, обогащенной ТФР. После туалета раны 3\% раствором перекиси водорода и кюретажа раневую поверхность закрывали раневым покрытием PCL, на которое наносили фибриновый сгусток. Через сутки во время второй перевязки остатки фибринового сгустка удаляли, а раневое покрытие орошали плазмой, обогащенной аутотромбоцитарным фактором роста.

Во всех наблюдениях пациентами было подписано соглашение об участии в исследовании. Весь перечень исследований и использованных методик лечения был одобрен этической комиссией Института общей и неотложной хирургии имени В. Т. Зайцева НАМН Украины.

\section{Результаты}

На фоне применения ФДТ раны очищались от гнойно-некротических масс на 2 - 3-и сут лечения. Первые грануляции появлялись на 4 - 5-е сут, а признаки краевой эпителизации - на 6 - 7-е сут. Некрозы уже после первого сеанса Фдт активно отторгались (в процессе лечения ни в одном наблюдении не потребовалось выполнения этапных некрэктомий). Продолжительность ФДТ составляла 5 - 7 сут в зависимости от исходного состояния ран. На фоне проводимого дальнейшего лечения с применением красного света к 2 - 3-м сут уменьшался перифокальный отек, к 5 - 7-м сут существенно улучшались качество грануляций и степень эпителизации ран. Площадь поверхности ран до начала лечения составила в среднем $(391,3 \pm 100,42)$ см$^{2}$, к $5-7-$ м сут лечения - $(364,7 \pm 44,21)$ см $^{2}$ и к $10-12-$ м сут - $(63,95 \pm$ $20,2) \mathrm{cm}^{2}(\mathrm{p}<0,01)$. Скорость заживления ран к $5-7-\mathrm{M}$ сут лечения составила $(1,58 \pm 0,44) \%$, к $10-12$ - сут $(4,72 \pm 0,63) \%(\mathrm{p}<0,01)$.

Аллергических реакций на ФС отмечено не было. На фоне проводимого лечения наблюдались позитивные изменения со стороны микробного пейзажа ран. При поступлении у пациентов выделяли в основном грамположительные микроорганизмы со средней колонизацией ран 7,42 × $10^{9}$ (колониеформирующих единиц КФЕ/г). На первом месте (у 4 пациентов) были стафилококки со средней колонизацией ран $(8,46 \pm 0,82) \times 10^{9}$ КФЕ/г, на втором месте (у 3 пациентов) - микрококки со средней колонизацией ран $(7,24 \pm 0,84) \times 10^{9} \mathrm{KФЕ/г,}$ на третьем (у 2 пациентов) - коринебактерии со средней колонизацией ран $(7,58 \pm 0,87) \times 10^{9}$ КФЕ/г. Аэробные спорообразующие палочки были в одном наблюдении, энтеробактерии - в одном и неферментирующие бактерии - также в одном со средней колонизацией ран $(7,14 \pm 0,74) \times 10^{9} \mathrm{KФЕ/г.} \mathrm{На} 3$ - 5-е сут исследования микробная контаминация ран уменьшалась, к 6 - 7-м сут уровень инфицированности ран был ниже критических величин (меньше 105), на 9 - 10-е сут не высевались стафилококки и стрептококки, а с $11-$ х сут - микрококки и энтеробактерии. Транскутанное напряжение кислорода к 5 - 7-м сут лечения у исследуемых пациентов составляло 67 - 80 Па.

Очевидно, в процессах очищения и снижения микробной контаминации ран велика роль способности нейтрофилов утилизировать возбудителей с помощью кислороднезависимого и кислородзависимого фагоцитоза. Комбинированное воздействие ФДТ и ТФР приводило к значительному сокращению длительности всех фаз раневого процесса благодаря активации фагоцито3a.

Максимальное увеличение ФИ нейтрофилов на фоне проведения ФТ наблюдали после воздействия зеленым светом $(\lambda=530$ нм $)$ - в среднем до 80,75\%, что соответствует референтным значениям этого показателя. Количество микробных тел, захваченных нейтрофилами (ФЧ), до лечения было ниже референтных значений, на всех этапах комплексной терапии наблюдали стимуляцию эндоцитоза (ФЧ достигал референтных значений).

Об эффективности фагоцитоза судили по конечной переваривающей способности нейтрофилов, которую определяли величиной индекса завершенного фагоцитоза (ИЗФ). На фоне проведения ФТ наблюдали эффективное увеличение эндоцитоза микробных антител. Максимальный процессинг на уровне референтных значений $(1,83)$ отмечали после воздействия зеленым светом $(\lambda=530$ нм $)$.

Наряду с позитивной стимуляцией кислороднезависимого фагоцитоза на фоне лечения наблюдали спонтанное изменение активности окислительных ферментов нейтрофилов: как до, так и после Фдт в НСТтесте наблюдали выраженное увеличение спонтан- 
ной прооксидантной функции нейтрофилов. Референтные значения для нейтрофилов, спонтанно поглощающих и окисляющих субстрат - диформазан, соответствовали 10\%, спонтанная окислительная активность нейтрофилов до лечения в несколько раз превышала нормальный спонтанный уровень (выше 35\%), что свидетельствовало о снижении окислительного резерва. На фоне проводимого комплекса лечебных мероприятий выявляли нормализацию индуцированного зимозаном образования АФК после воздействия красного $(\lambda=660$ нм) и синего $(\lambda$ $=440$ нм) света. То есть увеличение индуцированной окислительной способности нейтрофилов на фоне лечения способствовало нормализации окислительного резерва клеток и обеспечивало утилизацию патогенных микроорганизмов.

\section{Обсуждение}

Проведенные исследования показали, что использование ФТ и ФДТ в комплексе лечения больных с СДС способствовало более быстрому очищению ран, ускорению появления грануляций и эпителизации - соответственно на 2 - 3-и, 4 - 5-е и 6 - 7-е сут от начала лечения. При традиционном лечении согласно данным литературы [8], аналогичные изменения в длительно незаживающих ранах происходят соответственно в сроки 4 - 10, 10 - 11 и 11 - 15 сут. Подобный положительный эффект ФТ и ФдТ приводит к значительному увеличению скорости заживления ран.

Вместе с тем до полного понимания окончательного механизма положительного влияния ФТ и ФдТ еще далеко, однако некоторые его моменты сформулировать уже можно.

В регуляции смены стадий раневого процесса существенная роль принадлежит фагоцитирующим нейтрофилам, которые препятствуют экспансии патогенных микроорганизмов Известно, что эндотоксины в зависимости от концентрации двухфазно влияют на функциональную активность лейкоцитов [9]. Помимо микробных антигенов, в раневом процессе в качестве опсонинов функционируют антитела и факторы комплемента, на стадии воспаления они образуют с антигенами патогенные циркулирующие иммунные комплексы [7], а их дальнейший процессинг зависит от фагоцитоза, который снижен на фоне ингибирования лизосомальных ферментов и НАДН-оксидазы, что было показано в наших исследованиях кислороднезависимого и кислородзависмого фагоцитоза. Образующиеся в ране токсины ингибируют функциональную активность фагоцитирующих полиморфноядерных лейкоцитов и макрофагов, при этом страдают все стадии фагоцитоза. Вместе с тем очень трудной задачей лечения является медикаментозная активация фагоцитирующих антигенпрезентирующих клеток на фоне высокого уровня микробной контаминации ран и резистентности возбудителей инфек- ции. В результате сочетанного применения ФДТ и ТФР происходит стимуляция всех этапов процессинга антигена в результате активации кислороднезависимого эндоцитоза и «кислородного взрыва» в фагоцитирующих нейтрофилах. Световое воздействие различного диапазона и ТФР стимулировали фагоцитоз и процессы пролиферации, а также созревание грануляционной ткани и эпителизацию ран.

\section{Выводы}

1. Улучшение результатов лечения ран у больных с СДС при использовании предлагаемого подхода связано с бактерицидным эффектом ФДТ и ее способностью к активации фагоцитоза на этапе подготовки раны к пластическому закрытию, а также с активацией регенераторных процессов на фоне применения ТФР. При этом высокий уровень индукции ферментов ФС способствует нормализации иммунореактивности.

2. Несмотря на высокую спонтанную окислительную и низкую индуцированную активность фагоцитов, после светового воздействия окислительный резерв гранулоцитов возрастает. Комбинированное световое воздействие и использование ФС стимулирует образование АФК, что проявляется в активации процессинга антигенов. ФДТ усиливает молекулярные механизмы межклеточного взаимодействия на всех этапах активации первичного иммунитета.

\section{References}

1. Oksuz E, Malhan S, Sonmez B, Tekin RN. Cost of illness among patients with diabetic foot ulcer in Turkey. World J Diabetes. 2016 Oct 15;7(18):462-69. Published online 2016 Oct 15. doi: 10.4239/wjd. v7.i18.462.

2. Mottola C, Semedo-Lemsaddek T, Mendes JJ, Melo-Cristino J, Tavares L, Cavaco-Silva P, et al. Molecular typing, virulence traits and antimicrobial resistance of diabetic foot staphylococci. J Biomed Sci. 2016 Mar 8;23:33. doi: 10.1186/s12929-016-0250-7.

3. Skwor TA, Klemm S, Zhang H, Schardt B, Blaszczyk S, Bork MA Photodynamic inactivation of methicillin-resistant Staphylococcus aureus and Escherichia coli: A metalloporphyrin comparison. J Photochem Photobiol B. 2016 Dec;165:51-7. doi: 10.1016/j.jphotobiol.2016.10.016. Epub 2016 Oct 15.

4. Kuzin MI, Kostjuchenok BM. Rany i ranevaja infekcija. Moskva: Medicina; 1990. 592 p. [In Russian].

5. Peters EJ, Lavery LA. Effectiveness of the diabetic foot risk classification system of the International Working Group on the Diabetic Foot. Diabetes Care. 2001 Aug, 24(8):1442-7.

6. Korobov AM, Korobov VA, Lesnaja TA. Fototerapevticheskie apparaty Korobova serii «Barva». - Izd vtoroe, pererab i dop. Kharkov: IPP «Kontrast»; 2008. 176 p. [In Russian].

7. Filonenko EV, Serova LG. Fotodinamicheskaja terapija v klinicheskoj praktike. Biomedical Photonics. 2016, 5(2):26-37. [In Russian].

8. Janushko VA, Turljuk DV, Ladygin PA, et al. Sovremennye podhody diagnostiki i lechenija mnogourovnevyh porazhenij arterij nizhnih konechnostej nizhe pahovoj skladki v stadii kriticheskoj ishemii. Novosti hirurgii. 2011;19(6):115-28. [In Russian]. 